\title{
Differentiation capacity of native pituitary folliculostellate cells and brain astrocytes
}

\author{
Marumi Osuna $^{1,2}$, Yokiko Sonobe ${ }^{1}$, Eisuke Itakura ${ }^{1,3}$, Sukumar Devnath ${ }^{1,4}$, Takako Kato ${ }^{6}$, Yukio Kato ${ }^{2,5,6}$ \\ and Kinji Inoue ${ }^{1,7}$ \\ ${ }^{1}$ Graduate School of Science and Engineering, Saitama University, 255 Shimo-ohkubo, Sakura-ku, Saitama 338-8570, Japan \\ ${ }^{2}$ Division of Life Science, Graduate School of Agriculture, Meiji University, 1-1-1 Higashi-Mita, Tama-ku, Kanagawa 214-8571, Japan \\ ${ }^{3}$ Department of Physiology and Cell Biology, Tokyo Medical and Dental University, Tokyo 113-8519, Japan \\ ${ }^{4}$ School of Agriculture and Rural Development, Bangladesh Open University, Gazipur 1705, Bangladesh \\ ${ }^{5}$ Department of Life Science, School of Agriculture and ${ }^{6}$ Institute of Reproduction and Endocrinology, Meiji University, Kanagawa 214-8571, Japan \\ ${ }^{7}$ Research Management Bureau, Saitama University, 255 Shimo-ohkubo, Sakura-ku, Saitama 338-8570, Japan \\ (Correspondence should be addressed to K Inoue at Research Management Bureau, Saitama University; Email: kininoue@mail.saitama-u.ac.jp)
}

\begin{abstract}
Pituitary folliculostellate (FS) cells are characterized by producing S100B protein, as do brain astrocytes. FS cells have some functions in the pituitary gland, i.e. scavenger functions, sustentacular cell activity through cytokines, and intercellular communication through gap junctions. However, the biological significances of FS cells, especially their differentiation capacities in the anterior pituitary gland, are still under discussion. To understand FS cells with new approaches, we generated a transgenic rat expressing GFP under $S 100 b$ gene promoter, which regulates tissue-specific expression of $S 100 \mathrm{~b}$ gene. Using the transgenic rat, we

succeeded in inducing skeletal muscle cells from FS cells by culturing it in serum-free medium containing B-27 supplement, thyroid hormone (tri-iodothyronine), epidermal growth factor, and basic fibroblast growth factor. In this study, we also succeeded in inducing skeletal muscle cells from primary cultured astrocytes and astrocyte cell line, C6 cells. Hence, we concluded that pituitary FS cells have wide differentiation potential and have similar characteristics to astrocytes, which not only support cell activity but also support differentiation capacity.

Journal of Endocrinology (2012) 213, 231-237
\end{abstract}

\section{Introduction}

Pituitary folliculostellate (FS) cells are stellate and S100B protein-positive cells that surround neighboring endocrine cells by their long cytoplasmic processes, which are considered to act as a sustentacular cell in the pituitary gland. Such morphological characteristics resemble brain astrocytes. However, the biological significance of FS cells is still under discussion.

Pituitary FS cells do not produce any of the classic pituitary hormones, however; they regulate the microenvironment of anterior pituitary gland by surrounding endocrine cells with their cytoplasmic processes and by producing many kinds of growth factors and cytokines (Inoue et al. 1999, Allaerts \& Vankelecom 2005). We are interested in the differentiation capacity of FS cells, as some of the cells are suspected to act as stem cells in the pituitary gland (Inoue et al. 1999, Devnath \& Inoue 2008), similar to brain astrocytes (Laywell et al. 2000, Alvarez-Buylla \& Lim 2004). Although our previous studies showed that FS cells have a potential to differentiate into skeletal muscle cells (Inoue et al. 1987, Mogi et al. 2004), our data were obtained using cell line or grafted pituitary gland.
Therefore, we cannot neglect the abnormal differentiation potential of transformed cell lines or heterogeneous cells in the grafted tissue.

On the other hand, we recently generated S100b:GFP transgenic (S100b $\mathrm{Tg}$ ) rat to detect living normal FS cells and astrocytes (Itakura et al. 2007) because S100B protein is specifically produced by FS cells in the anterior pituitary gland and also astrocytes in the brain. Therefore, we used $\mathrm{S} 100 \mathrm{~b} \mathrm{Tg}$ rats and studied the differentiation capacity of FS cells and astrocytes. Here, we report that pituitary FS cells and brain astrocytes have the potential to differentiate into skeletal muscle cells and we discuss the differentiation capacity of those cells.

\section{Materials and Methods}

\section{Animals}

S100b:GFP transgenic (S100b $\mathrm{Tg}$ ) rats were generated as described previously (Itakura et al. 2007) and were housed individually in a temperature-controlled $\left(22-24^{\circ} \mathrm{C}\right)$ room 
under a $12 \mathrm{~h}$ light: $12 \mathrm{~h}$ darkness cycle. All experiments were conducted in accordance with the institutional guidelines for animal care of Saitama University, which follows NIH guidelines.

\section{Isolation and cultivation of FS cells and astrocytes from S100b $\mathrm{Tg}$ rats}

GFP-expressing FS cells were isolated from the anterior pituitaries of S100b Tg rats (over 14 weeks old). The S100b $\mathrm{Tg}$ rats are effective for detection and observation of living FS cells with cell-specific expression of GFP (Itakura et al. 2007). Anterior lobes of pituitary glands were chopped and digested with collagenase, and the suspended cells were sorted with a cell sorter (EPICS Elite, Beckman Coulter, Inc., Brea, CA, USA). Isolated cells were seeded on rat tail's collagencoated 48-well plate (three wells for each group) or $35 \mathrm{~mm}^{2}$ dishes at $3 \cdot 5-5 \times 10^{4}$ cells $/ \mathrm{ml}$ and cultured in a medium composed of half DMEM (Life Technologies, Inc.), half Ham F-12 (Life Technologies) (D/F medium) supplemented with 10\% donor horse serum (DHS; Nichimen America, Los Angeles, CA, USA), and 2.5\% fetal bovine serum (FBS; Biological Industries, Ltd., Beit-Haemek, Israel). The cells were cultured in a water-jacketed $\mathrm{CO}_{2}$ incubator $\left(5 \% \mathrm{CO}_{2}\right.$ and $95 \%$ air) at $37^{\circ} \mathrm{C}$.

Astrocytes from cerebral neocortexes were isolated from 1- or 2-day-old S100b $\mathrm{Tg}$ rats according to the procedure followed in a previous report (Cristiano et al. 2005). Briefly, rats were deeply anesthetized and the neocortex was separated. Then, the meninges were carefully excised. The neocortex cells were mechanically dissociated by passages through needles (20G and 27G). After the dissociation with $0.025 \%$ trypsin in PBS, neocortex cells were seeded at $5-10 \times 10^{4}$ cells $/ \mathrm{ml}$ in $\mathrm{D} / \mathrm{F}$ medium supplemented with $10 \%$ DHS and $2 \cdot 5 \%$ FBS at $37^{\circ} \mathrm{C}$. The culture medium was changed after 4 days of seeding and subsequently every other day. After 10 days of culture, neocortex cells in flasks were shaken overnight by a shaker to isolate astrocytes using their specific strong adherence to the bottom of flasks (McCarthy \& de Vellis 1980). Adhered astrocytes were suspended with $0.025 \%$ trypsin and $0.02 \mathrm{mM}$ EDTA and seeded on rat tail's collagen-coated $35 \mathrm{~mm}^{2}$ dishes at $2-2 \cdot 5 \times 10^{4}$ cells $/ \mathrm{ml}$ in the $\mathrm{D} / \mathrm{F}$ medium. For the time course experiment, FS cells or astrocytes were seeded on rat tail's collagen-coated $35 \mathrm{~mm}^{2}$ glass bottom dishes (Matsunami Glass Ind., Ltd., Osaka, Japan), which has grids to trace the targeted cell in the induction for skeletal muscle cells. C6 cells (Health Science Research Resources Bank, Osaka, Japan) were obtained and cultured in D/F medium supplemented with $10 \%$ DHS and $2 \cdot 5 \%$ FBS.

\section{Induction of skeletal muscle cells from FS cells and astrocytes}

The sorted FS cells were cultured for 10 days in a differentiation medium, i.e. serum-free medium (3:1 of DMEM and Ham F-12), which was supplemented with
2\% B27 supplement (Invitrogen Corp.), $10^{-6} \mathrm{M}$ thyroid hormone (tri-iodothyronine ( $\left.\mathrm{T}_{3}\right)$; Sigma Co.), $20 \mathrm{ng} / \mathrm{ml}$ epidermal growth factor (EGF; Wako Pure Chemical Industries, Ltd., Osaka, Japan), and $40 \mathrm{ng} / \mathrm{ml}$ recombinant human fibroblast growth factor (bFGF; Takeda, Osaka, Japan).

For the induction of astrocytes or C6 cells, they were treated for 3 days in the D/F medium containing serum and $20 \mu \mathrm{M} 5^{\prime}$-azacytidine (Sigma Co.). After the treatment, astrocytes were replaced in the serum-free medium (3:1 of DMEM and Ham F-12), which is supplemented with B27 supplement and $10^{-6} \mathrm{M} \mathrm{T}_{3}$. For the induction of C6 cells, the differentiation medium was additionally supplemented with $20 \mathrm{ng} / \mathrm{ml}$ EGF and $40 \mathrm{ng} / \mathrm{ml}$ bFGF and serum ( $2 \%$ DHS and $0 \cdot 5 \%$ FBS). These cells were incubated at $37^{\circ} \mathrm{C}$ for 10 days.

\section{Immunocytochemistry}

The cells on culture dishes were fixed with $4 \%$ paraformaldehyde in PBS for $30 \mathrm{~min}$. After pretreatment with PBS containing $1 \%$ FBS and $0 \cdot 4 \%$ Triton X-100 for $1 \mathrm{~h}$, the cells were incubated overnight with the first antibodies for myogenin (1:1000; Santa Cruz Biotechnology, Inc., Santa Cruz, CA, USA) and myoglobin (1:1000). Following incubation with the Alexa fluor 594/488 donkey anti-rabbit/ mouse IgG antibody, cell nuclei were counterstained with $4^{\prime}, 6$-diamidino-2-phenylindole (DAPI) and then visualized by fluorescence microscopy. In the time course experiment, the cells cultured for 10 days in the differentiation medium and were incubated with the anti-rat IgG antibody (Vector Laboratories, Inc., Burlingame, CA, USA) for $2 \mathrm{~h}$ after the first antibody reaction for myoglobin and then with a biotinavidin immunocomplex (VECTASTAIN ABC KIT; Vector Laboratories) for $30 \mathrm{~min}$. The immunoreaction was detected by staining with a diaminobenzidine solution.

\section{Reverse transcription and quantitative RT-PCR}

Total RNA was extracted from the induced cells using ISOGEN (Nippon Gene Co., Tokyo, Japan) according to the manufacturer's instructions. cDNA was synthesized from about $750 \mathrm{ng}$ total RNA using Prime Script reverse transcriptase (Takara Bio, Shiga, Japan) with random primer (Invitrogen Corp.). Quantitative PCR was performed using the LightCycler system with SYBR Premix EX Taq (Takara Bio) according to the manufacturer's recommendations. The following primers were used: myogenin, forward 5'-CAGTGAATGCAACTCCCACA-3', reverse $5^{\prime}$-CATGGTTTCATCTGGGAAGG-3'; S100b, forward $5^{\prime}$-GTCCACACCCAGTCCTCTCT- $3^{\prime}$, reverse $5^{\prime}$-TTCAGCTTGTGCTTGTCACC- $3^{\prime}$; and $18 S$ rRNA (internal control RNA for the normalization), forward 5'-CGGCTACCACATCCAAGGAA- $3^{\prime}$, reverse $5^{\prime}$-ATTGGAGCTGGAATTACCGC- $3^{\prime}$. Relative mRNA ratio was derived after normalization to $18 \mathrm{~S}$. 

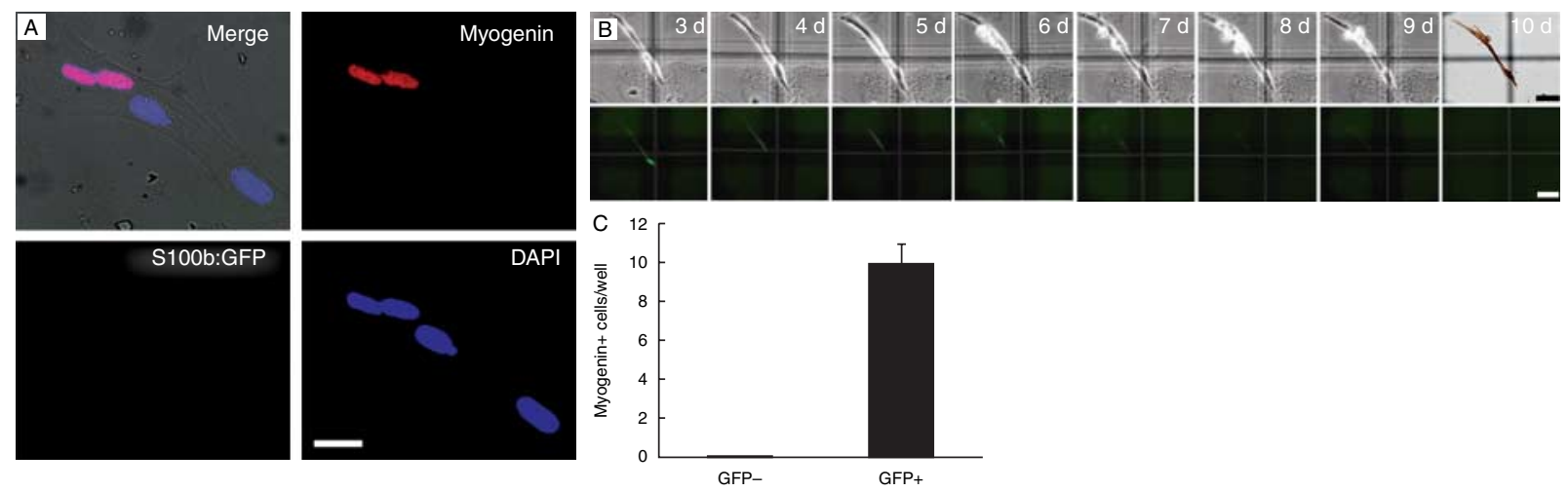

Figure 1 Differentiation of FS cells of the anterior pituitary gland into skeletal muscle. (A) Skeletal muscle cells appeared in the culture of isolated pituitary FS cells. Myogenin (red), a skeletal muscle cell marker, was detected by immunocytochemistry. The detected skeletal muscle cells were S100b:GFP negative (green). Nuclei were counterstained with DAPI (blue). Bar represents $20 \mu \mathrm{m}$. (B) FS cells from S100b Tg rat were traced with their S100b:GFP expression in the culture. Traced cells had a straight shape and decreased its S100b:GFP expression, which were eventually positive against myoglobin (10d, top). ' $d$ ' represents days from the beginning of the observations. Top: phase contrast. Bottom: S100b:GFP. Bars represent $50 \mu \mathrm{m}$. (C) S100b:GFP-positive/negative cells were sorted and cultured in the same differentiation medium. Myogenin-positive cells were induced only from GFP-positive cell group $(10 \pm 1$ cells/739 \pm 74 cells) while there were no myogenin-positive cells in GFP-negative cell group $(0 \pm 0$ cells/36 \pm 11 cells). GFP-, S100b:GFP-negative cell group; GFP+, S100b:GFPpositive cell group. Bar represents mean \pm s.D.

\section{Results}

\section{Differentiation of pituitary FS cells into skeletal muscle cells}

In our first experiment, we isolated GFP-positive FS cells from pituitary gland by a cell sorter and cultured in a serumfree medium-added B27 supplement, $\mathrm{T}_{3}$, EGF, and bFGF. As shown in Fig. 1A, we found myogenin-positive cells in the cultured anterior pituitary cells. Some myogenin-positive cells were multinucleated and spindle shaped. In order to trace the origin of skeletal muscle cells, the S100b:GFPpositive FS cells (Supplementary Figure 1A, see section on supplementary data given at the end of this article) were traced with a time course experiment. As shown in Fig. 1B, spindle-shaped and S100b:GFP-expressing cells gradually decreased their S100b:GFP intensity in the culture. Finally, the traced cells became myoglobin positive, which indicates that FS cells differentiated into skeletal muscle cells. Also, GFP-positive cells shown at the beginning of trace had low GFP signal (Fig. 1B, 3d) and then those skeletal muscle cells found in the culture lost their S100b:GFP expression (Fig. 1A and B). This would suggest that the traced cell had already started to differentiate into a skeletal muscle cell that does not express $\mathrm{S} 100 \mathrm{~b}$ gene, like somatic skeletal muscle cells. The quantitative study also showed that myogenin-positive cells were observed only in the S100b:GFP-positive cell. Although the sorted GFPpositive/negative cell groups were respectively cultured in the same condition, we found $10 \pm 1$ myogenin-positive cells in the GFP-positive cell group ( $1 \cdot 4 \%$ of total $739 \pm 74$ cells/ well) and no myogenin-positive cells in the GFP-negative cell group (total $36 \pm 11$ cells/well) (Fig. 1C). This suggests that the differentiation into skeletal muscle cells in the culture was restricted to FS cells.

\section{Differentiation of brain astrocytes into skeletal muscle cells}

To induce skeletal muscle cells, astrocytes were isolated from the cerebral neocortex of rats and were cultured in a serumfree medium with B27 supplement, $\mathrm{T}_{3}, \mathrm{EGF}$, and bFGF. However, no skeletal muscle cell appeared, unlike pituitary FS cells. Therefore, we treated astrocytes with $5^{\prime}$-azacytidine, a DNA demethylation agent, to trigger the differentiation potential of astrocytes. After 10 days of cultivation, some tubular cells appeared in cultured astrocytes (Fig. 2A; left). Most of these cells had multinuclei and were positive against the specific protein of skeletal muscle cells, myoglobin and
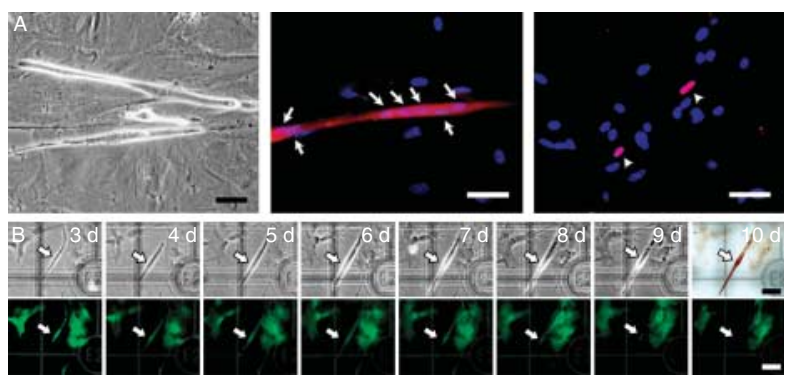

Figure 2 Skeletal muscle cell characteristics appeared in cultured astrocytes. (A) Muscle cells induced from astrocytes, which were cultured with the differentiation medium for 10 days after the treatment with $5^{\prime}$-azacytidine. The myoglobin-positive cell was multinuclear (arrows): left, phase contrast; middle, myoglobin (red); right, myogenin (red, arrowheads). Nuclei were counterstained with DAPI (blue). Bars represent $50 \mu \mathrm{m}$. (B) S100b:GFP-positive astrocytes of $\mathrm{S} 100 \mathrm{~b} \mathrm{Tg}$ rats were traced in the culture. Contraction of a cell (arrows) was observed at the sixth day $(6 \mathrm{~d}$, Supplementary Movie 1). Cells were finally fixed and stained with antibody against myoglobin (10d, top). ' $d$ ' represents days from the beginning of the observation. Top: phase contrast. Bottom: S100b:GFP. Scale bar represents $50 \mu \mathrm{m}$. 

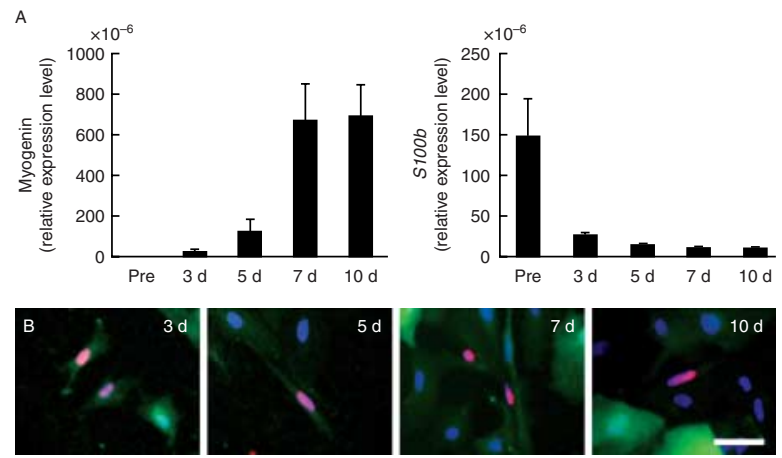

Figure 3 Time course changes of FS cell marker, S100b, and a muscle-specific marker, myogenin. (A) After treatment with $5^{\prime}$-azacytidine, astrocytes were cultured in the differentiation medium and analyzed at each point. Expression levels of myogenin mRNA and $S 100 b$ mRNA of each point in cultured cells were measured by quantitative PCR. Bars represent mean \pm S.E.M. Both mRNAs were normalized with $18 \mathrm{~s}$ rRNA. 'pre' means isolated astrocytes before the treatment of $5^{\prime}$-azacytidine. The other days $(3 d, 5 d, 7 d$, and $10 d)$ represent incubation time in the differentiation medium. (B) Coexistence of myogenin (red) and S100b:GFP (green) at each time point (3d, 5d, $7 d$, and $10 d)$ was detected by immunocytochemistry. The coexistence of S100b:GFP and myogenin was observed at $3 \mathrm{~d}$ and $5 \mathrm{~d}$. Bar represents $50 \mu \mathrm{m}$.

myogenin (Fig. 2A; middle and right). Myogenin-positive cells in the culture of astrocytes were observed in a proportion of $0 \cdot 6 \%$ (data not shown). This suggests that cultured astrocytes might differentiate into skeletal muscle cells.

To confirm our finding, we used S100b Tg rats, which enabled us to trace astrocytes with S100b:GFP expression. By the time course observation of astrocytes, we succeeded in tracing the differentiation process of astrocytes into skeletal muscle cells (Fig. 2B). On the first day of induction in differentiation medium, there was no muscle-like cell in the culture (Supplementary Figure 1B). Three days after beginning induction, astrocytes expressing S100b:GFP became longer and thicker like a tubular muscle cell. On the sixth day of induction, the cell started contracting autonomously (Supplementary Movie 1, see section on supplementary data given at the end of this article). Finally, we stained cultured cells by immunocytochemistry and found that the muscle cells were positive against myoglobin (Fig. 2B).

\section{Quantitative experiment of skeletal muscle cell differentiation from astrocytes}

We next performed a quantitative experiment in connection with the appearance of myogenin, a transcript factor known to act in the early stage of differentiation of skeletal muscle cells. The mRNA level of myogenin gradually increased (Fig. 3A; left) and was especially high at the seventh and tenth day from the induction. In contrast, mRNA level of $S 100 b$ was dramatically reduced after treatment with $5^{\prime}$-azacytidine (from 'pre' to ' $3 \mathrm{~d}$ ') and gradually decreased from the third to the tenth day (Fig. 3A; right). This would again suggest that the developed skeletal muscle cells do not express the $S 100 \mathrm{~b}$ gene. Actually, intracellular colocalizations of myogenin and S100b:GFP were different between the early and later stage of induction, i.e. colocalization of S100b:GFP signal, and myogenin was observed on the third and fifth day after induction, whereas it was not observed on the seventh or tenth day (Fig. 3B).

\section{Differentiation of astrocyte cell line, C6 cells, into skeletal muscle cells}

Our finding was confirmed using astrocyte-derived cell line, C6. The C6 cells are a well-characterized astrocyte cell line (Benda et al. 1968). Similarly, in our study of astrocyte induction, we treated C6 cells with $5^{\prime}$-azacytidine for 3 days and then cultured them in a differentiation medium supplemented with B27, $\mathrm{T}_{3}$, EGF, and bFGF. Ten days after beginning induction, C6 cells were stained with antibodies against myogenin and myoglobin. We found skeletal muscle cells in cultured C6 cells, which were morphologically long and straight and positive against myogenin (green) and myoglobin (red) (Fig. 4). Myogenin-positive cells accounted for $<1.5 \%$. The cell line experiment indicates that skeletal muscle cells found in primary cultured astrocytes were not from other contaminated cells, i.e. we clearly demonstrated the differentiation of astrocytes into skeletal muscle cells.

\section{Discussion}

This study used S100b Tg rats, which express GFP in S100B protein-producing cells such as pituitary FS cells and astrocytes. Transgenic rats are very useful and allow us to observe living FS cells or astrocytes. Using this system, we
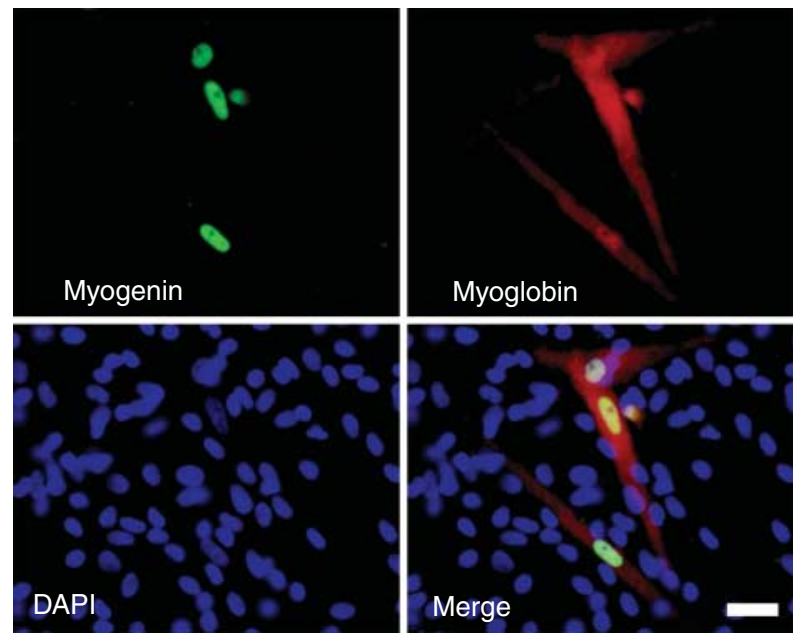

Figure 4 Skeletal muscle cells differentiated from C6 astrocyte cell line. Skeletal muscle cells derived from $\mathrm{C} 6$ cells were stained with antibodies against myoglobin (red) and myogenin (green). Nuclei were counterstained with DAPI (blue). Scale bar represents $25 \mu \mathrm{m}$. 
concluded that pituitary FS cells have the potential to differentiate into skeletal muscle cells (Fig. 1).

The differentiation capacity of FS cells into skeletal muscle cells may suggest that some of the FS cells are multipotent and contribute to a self-renewal system of the anterior pituitary gland. However, it has also not been clearly shown that FS cells act as stem cells in the anterior pituitary gland; the morphological observation that FS cells closely associate with immature endocrine cells suggests that FS cells are involved in their differentiation (Inoue et al. 1999). Recently, some S100B-positive FS cells have been reported to express a stem cell marker and a pituitary precursor marker, SOX2 and PROP1, respectively (Yoshida et al. 2011), which suggests that FS cells have a wide differentiation capacity like organ-specific stem cells. However, it should be recalled that S100B-positive FS cells in the anterior pituitary gland are heterogeneous in origin and are composed of subpopulations with a different potential for differentiation or functional capacity.

In this study, we also found that brain astrocytes had capacity to differentiate into skeletal muscle cells (Figs 2, 3 and 4). Astrocytes have characteristics similar to pituitary FS cells, i.e. they act as supportive cells and produce $\mathrm{S} 100 \mathrm{~B}$ protein specifically in the brain and in the pituitary gland (Koehler et al. 2006, Straub \& Nelson 2007). Some astrocytes may reportedly act as neural stem cells in the brain and form neurospheres, which can generate neurons and glial cells (Laywell et al. 2000, Alvarez-Buylla \& Lim 2004, Ihrie \& Alvarez-Buylla 2008). Although the reported differentiation potential of astrocytes is restricted to the neurons or glial cells, this study shows that astrocytes can also differentiate to express a number of key characteristics of muscle. However, the differentiation capacity of FS cells and astrocytes into skeletal muscle has been shown; the FS cells/astrocytes and muscle cells originate from completely different embryonic layers, ectoderm and mesoderm, respectively. Therefore, our finding reveals their unexpected differentiation.

On the other hand, the most recent labeling experiments of rat/mouse embryo showed that cells derived from the rostral end of neural plate/the anterior neural ridge migrated and composed of Rathke's pouch, which is the primordium of the adenohypophysis (Osumi-Yamashita et al. 1994, Kouki et al. 2001). It was also reported that Rathke's pouch was entirely made up of anterior neural ridge-derived cells at E5 of chicken embryo while no neural crest-derived cells existed (Couly \& Le Douarin 1985), and mesenchymal cells surrounding the primordium were from neural crest-derived cells (Couly \& Le Douarin 1987). The neural crest is a temporal structure formed at the lateral border of the neural plate and epidermis of a vertebrate embryo. The cells composing the neural crest migrate widely throughout an embryo after an epithelial-mesenchymal transition. It is also suggested that multipotent neural crest cells contribute to tissue formation (Le Lievre \& Le Douarin 1975, Le Douarin et al. 2004, Dupin et al. 2007). Cultured cephalic neural crest cells of quail embryo show characteristics of stem cells, namely self-renewal and wide differentiation capacity into neuron, glia, pigment cell, myofibroblast, and cartilage (Trentin et al. 2004). In the later developmental stage (E12 of chicken embryo), the neural crest-derived interstitial cells and pericytes infiltrated the adenohypophysis where they served to form connective tissue (Etchevers et al. 2001). These reports suggest that neural crest-derived cells are present in the anterior pituitary gland. Cultured normal human brain astrocytes also reportedly expressed neural crest cell markers, SOX10 and p75 (Rieske et al. 2009). We propose a hypothesis that some FS cells and astrocytes originate from a neural crest. Some of them might maintain the characteristics of neural crest cells and show differentiation capacity in this study. However, further study is needed to prove the above hypothesis using a transgenic animal in which neural crest cells are genetically labeled and traced in a further stage of development.

Although this study shows that FS cells and astrocytes have differentiation potential, the cell-transforming proportion was low in both FS cells $(1 \cdot 4 \%$, Fig. 1C) and astrocytes $(0 \cdot 6 \%)$. We consider that the low proportion of differentiation as in FS cells/astrocytes is not homogeneous even though they both express S100b. FS cells are known to have some functions in the anterior pituitary gland, i.e. supporting neighbor cells by secreting cytokines, scavenger function, and transferring signals through cell-cell gap junctions (Inoue et al. 1999, Allaerts \& Vankelecom 2005). In addition, S100B-positive FS cells could be classified into some types by expressing factors such as glial fibrillary acidic protein and keratin (Allaerts \& Vankelecom 2005), or SOX2 and PROP1 (Yoshida et al. 2011). Also, astrocytes are known to have several functions, for instance, as supportive cells and neural stem cells (Koehler et al. 2006, Ihrie \& Alvarez-Buylla 2008). These reports suggest that FS cells/astrocytes are heterogeneous and share their functions with their subpopulations. In this study, one subpopulation of S100B-positive FS cells/ astrocytes may well have shown differentiation capacity, which works for self-renewal system in their tissues.

On the other hand, the homogeneous C6 cell line also showed a low proportion of differentiation $(<1 \cdot 5 \%)$. As shown by research in regenerative medicine using embryonic stem cells or induced pluripotent stem cells, it is difficult to induce all homogeneous cells into one differentiated cell, even if they are pluripotent (Mizuno et al. 2010). This could be because of the condition of each cell among cultured cells. Eventually, further study is warranted to identify an effective factor to induce a high proportion of differentiated cells. Of the factors used in the present investigation, retinoic acid (RA) in B27 supplement and $\mathrm{T}_{3}$ may act efficiently to induce skeletal muscle cells. It is also reported that $\mathrm{T}_{3}$ is indeed a key factor in the differentiation of skeletal muscle (Nagase et al. 1999, Baumgartner et al. 2007). Previous studies reported that the heterodimer of receptors for $\mathrm{RA}$ and $\mathrm{T}_{3}$ was bound with the promoter of myogenin gene (Downes et al. 1993). To clarify the effects of RA and $\mathrm{T}_{3}$ on differentiation, further study is warranted. 
In conclusion, FS cells are present in the anterior pituitary gland of many species including human in common and surrounding endocrine cells. Also, FS cells and astrocytes share similar characteristics such as a stellate morphology and producing S100B protein. However, although FS cells seem to have important roles for endocrine cells of the pituitary gland, their biological significance has not been clear even though similar astrocytes are well studied and it has been demonstrated that astrocytes have some roles as sustentacular cells or neural stem cells in the brain. By showing the same differentiation capacity of astrocytes and FS cells, we would like to suggest that FS cells have a biological significance in the pituitary gland similar to that of astrocytes in the central nervous system, i.e. FS cells might not only support endocrine cells but also have a role in the self-renewal system of the pituitary gland. This gland has important endocrine function through secreting hormones, and its self-renewal system is well worth studying in this field. Our striking results underscore the need to discuss the roles of FS cells scattered throughout the anterior pituitary gland; they may relate to microenvironment regulation.

\section{Supplementary data}

This is linked to the online version of the paper at http://dx.doi.org/10.1530/ JOE-12-0043.

\section{Declaration of interest}

The authors declare that there is no conflict of interest that could be perceived as prejudicing the impartiality of the research reported.

\section{Funding}

This research did not receive any specific grant from any funding agency in the public, commercial or not-for-profit sector.

\section{References}

Allaerts W \& Vankelecom H 2005 History and perspectives of pituitary folliculo-stellate cell research. European Journal of Endocrinology 153 1-12. (doi:10.1530/eje.1.01949)

Alvarez-Buylla A \& Lim DA 2004 For the long run: maintaining germinal niches in the adult brain. Neuron 41 683-686. (doi:10.1016/S08966273(04)00111-4)

Benda P, Lightbody J, Sato G, Levine L \& Sweet W 1968 Differentiated rat glial cell strain in tissue culture. Science 161 370-371.

Baumgartner BG, Orpinell M, Duran J, Ribas V, Burghardt HE, Bach D, Villar AV, Paz JC, Gonzalez M, Camps M et al. 2007 Identification of a novel modulator of thyroid hormone receptor-mediated action. PLoS ONE 2 e1183. (doi:10.1371/journal.pone.0001183)

Couly GF \& Le Douarin NM 1985 Mapping of the early neural primordium in quail-chick chimeras. I. Developmental relationships between placodes, facial ectoderm, and prosencephalon. Developmental Biology $110422-439$. (doi:10.1016/0012-1606(85)90101-0)

Couly GF \& Le Douarin NM 1987 Mapping of the early neural primordium in quail-chick chimeras. II. The prosencephalic neural plate and neural folds: implications for the genesis of cephalic human congenital abnormalities. Developmental Biology 120 198-214. (doi:10.1016/00121606(87)90118-7)

Cristiano L, Cimini A, Moreno S, Ragnelli AM \& Paola Ceru M 2005 Peroxisome proliferator-activated receptors (PPARs) and related transcription factors in differentiating astrocyte cultures. Neuroscience $\mathbf{1 3 1}$ 577-587. (doi:10.1016/j.neuroscience.2004.11.008)

Devnath S \& Inoue K 2008 An insight to pituitary folliculo-stellate cells. Journal of Neuroendocrinology 20 687-691. (doi:10.1111/j.1365-2826.2008. 01716.x)

Downes M, Griggs R, Atkins A, Olson EN \& Muscat GE 1993 Identification of a thyroid hormone response element in the mouse myogenin gene: characterization of the thyroid hormone and retinoid $\mathrm{X}$ receptor heterodimeric binding site. Cell Growth \& Differentiation 4 901-909.

Dupin E, Calloni G, Real C, Goncalves-Trentin A \& Le Douarin NM 2007 Neural crest progenitors and stem cells. Comptes Rendus Biologies 330 521-529. (doi:10.1016/j.crvi.2007.04.004)

Etchevers HC, Vincent C, Le Douarin NM \& Couly GF 2001 The cephalic neural crest provides pericytes and smooth muscle cells to all blood vessels of the face and forebrain. Development 128 1059-1068.

Ihrie RA \& Alvarez-Buylla A 2008 Cells in the astroglial lineage are neural stem cells. Cell and Tissue Research 331 179-191. (doi:10.1007/s00441-007-0461-z)

Inoue K, Taniguchi Y \& Kurosumi K 1987 Differentiation of striated muscle fibers in pituitary gland grafts transplanted beneath the kidney capsule. Archivum Histologicum Japonicum 50 567-578. (doi:10.1679/aohc.50.567)

Inoue K, Couch EF, Takano K \& Ogawa S 1999 The structure and function of folliculo-stellate cells in the anterior pituitary gland. Archives of Histology and Cytology 62 205-218. (doi:10.1679/aohc.62.205)

Itakura E, Odaira K, Yokoyama K, Osuna M, Hara T \& Inoue K 2007 Generation of transgenic rats expressing green fluorescent protein in S-100beta-producing pituitary folliculo-stellate cells and brain astrocytes. Endocrinology 148 1518-1523. (doi:10.1210/en.2006-1390)

Koehler RC, Gebremedhin D \& Harder DR 2006 Role of astrocytes in cerebrovascular regulation. Journal of Applied Physiology 100 307-317. (doi:10.1152/japplphysiol.00938.2005)

Kouki T, Imai H, Aoto K, Eto K, Shioda S, Kawamura K \& Kikuyama S 2001 Developmental origin of the rat adenohypophysis prior to the formation of Rathke's pouch. Development 128 959-963.

Laywell ED, Rakic P, Kukekov VG, Holland EC \& Steindler DA 2000 Identification of a multipotent astrocytic stem cell in the immature and adult mouse brain. PNAS 97 13883-13888. (doi:10.1073/pnas. 250471697)

Le Douarin NM, Creuzet S, Couly G \& Dupin E 2004 Neural crest cell plasticity and its limits. Development 131 4637-4650. (doi:10.1242/ dev.01350)

Le Lievre CS \& Le Douarin NM 1975 Mesenchymal derivatives of the neural crest: analysis of chimaeric quail and chick embryos. Journal of Embryology and Experimental Morphology 34 125-154.

McCarthy KD \& de Vellis J 1980 Preparation of separate astroglial and oligodendroglial cell cultures from rat cerebral tissue. Journal of Cell Biology 85 890-902. (doi:10.1083/jcb.85.3.890)

Mizuno Y, Chang H, Umeda K, Niwa A, Iwasa T, Awaya T, Fukada S, Yamamoto H, Yamanaka S, Nakahata T et al. 2010 Generation of skeletal muscle stem/progenitor cells from murine induced pluripotent stem cells. FASEB Journal 24 2445-2453. (doi:10.1096/fj.09-137174)

Mogi C, Miyai S, Nishimura Y, Fukuro H, Yokoyama K, Takaki A \& Inoue K 2004 Differentiation of skeletal muscle from pituitary folliculo-stellate cells and endocrine progenitor cells. Experimental Cell Research 292 288-294. (doi:10.1016/j.yexcr.2003.09.018)

Nagase I, Yoshida S, Canas X, Irie Y, Kimura K, Yoshida T \& Saito M 1999 Up-regulation of uncoupling protein 3 by thyroid hormone, peroxisome proliferator-activated receptor ligands and 9-cis retinoic acid in L6 myotubes. FEBS Letters 461 319-322. (doi:10.1016/S0014-5793(99) 01477-5)

Osumi-Yamashita N, Ninomiya Y, Doi H \& Eto K 1994 The contribution of both forebrain and midbrain crest cells to the mesenchyme in the frontonasal mass of mouse embryos. Developmental Biology 164 409-419. (doi:10.1006/dbio.1994.1211) 
Rieske P, Augelli BJ, Stawski R, Gaughan J, Azizi SA \& Krynska B 2009 A population of human brain cells expressing phenotypic markers of more than one lineage can be induced in vitro to differentiate into mesenchymal cells. Experimental Cell Research 315 462-473. (doi:10.1016/j.yexcr.2008. 11.004)

Straub SV \& Nelson MT 2007 Astrocytic calcium signaling: the information currency coupling neuronal activity to the cerebral microcirculation. Trends in Cardiovascular Medicine 17 183-190. (doi:10.1016/j.tcm.2007.05.001)

Trentin A, Glavieux-Pardanaud C, Le Douarin NM \& Dupin E 2004 Self-renewal capacity is a widespread property of various types of neural crest precursor cells. PNAS 101 4495-4500. (doi:10.1073/pnas. 0400629101)
Yoshida S, Kato T, Yako H, Susa T, Cai LY, Osuna M, Inoue K \& Kato Y 2011 Significant quantitative and qualitative transition in pituitary stem/progenitor cells occurs during the postnatal development of the rat anterior pituitary. Journal of Neuroendocrinology 23 933-943. (doi:10.1111/j.13652826.2011.02198.x)

Received in final form 18 March 2012

Accepted 20 March 2012

Made available online as an Accepted Preprint 20 March 2012 